\title{
SPECTRUM OF ADVERSE EFFECTS OF HAART THERAPY AMONG HIV INFECTED INDIVIDUALS- A PROSPECTIVE STUDY
}

\author{
K. S. S. Venkateswara Rao ${ }^{1}$, V. Sreenivasulu ${ }^{2}$
}

1 Professor and HOD, Department of Medicine, Government Medical College, Anantapuramu. ${ }^{2}$ Associate Professor, Department of Medicine, Government Medical College, Anantapuramu.

\section{ABSTRACT}

\section{BACKGROUND}

India is the world's second largest country with HIV. The prevalence of HIV among Indian adults is $0.26 \%$. In 2015 , India had 2.1 million people living with HIV. HAART has reduced HIV mortality significantly. It is clear now that prolonged treatment that maintains suppression of plasma viraemia is unlikely to eradicate HIV. Therefore, therapy must be lifelong. Unfortunately, up to $25 \%$ of individuals discontinue HAART due to treatment failure, toxic effects or noncompliance.

The aim of the study is to study prospectively various HAART drugs induced adverse reactions among HIV patients within 6 months of therapy. To evaluate the correlation between the adverse drug reactions with various demographic factors, clinical symptoms at the time of initiation of treatment, CD4 count at the baseline and various HAART regime.

\section{MATERIALS AND METHODS}

200 HIV patients who fulfilled the NACO Guidelines for HAART therapy were started on treatment. All the investigations were done as per NACO Guidelines - Hb\%, RBC indices, TC, DC, platelet count, peripheral smear morphology, blood sugar, lipid profile and CD4 count. Categorical measurements are presented in number (\%). Chi-square test has been used to find out the significance of study parameters on categorical scale between 2 or more groups.

\section{RESULTS}

Out of 200 patients who were prospectively studied from January 2015 to October $2016,60 \%$ had various adverse drug reactions. The M:F was 1.2:1 with a mean age of $37.2 \pm 8.5$ (23-66 yrs.), $32.1 \pm 10.1$ (16-70 yrs.), respectively. None of the demographic factors showed any relation with ADR. Gastrointestinal manifestations are most common ADR (40.8\%) followed by fatigue (25.9\%). Nevirapine base regime significantly associated with dermatological manifestations $(\mathrm{p}=0.008)$. Peripheral neuropathy correlated significantly with the stavudine usage $(\mathrm{p}=0.05)$. None of our patients were noncompliant with treatment.

\section{CONCLUSION}

Adverse drug reactions are common during early part of HAART. Gastrointestinal manifestations are most common during this period. Most of the adverse drug reactions can easily recognised and early treatment will not affect the adherence pattern with HAART.

\section{KEYWORDS}

HIV, HAART Therapy, Adverse Effects.

HOW TO CITE THIS ARTICLE: Rao KSSV, Sreenivasulu V. Spectrum of adverse effects of HAART therapy among HIV infected individuals- A prospective study. J. Evolution Med. Dent. Sci. 2017;6(59):4379-4383, DOI: 10.14260/Jemds/2017/947

\section{BACKGROUND}

India is the world's second largest country with HIV. HIV virus was first recognised in India in 1986. One of every 6 HIV patients is in India. The prevalence of HIV among Indian adults is $0.26 \%$. In 2015, India had 2.1 million people living with HIV. HAART has reduced HIV mortality significantly. It is clear now that prolonged treatment that maintains suppression of plasma viraemia is unlikely to eradicate HIV. Unfortunately, up to $25 \%$ of individuals discontinue HAART due to treatment failure, toxic effects or noncompliance. Moreover, adverse drug effects have been increasingly recognised recently as the incidence of

Financial or Other, Competing Interest: None.

Submission 24-05-2017, Peer Review 15-06-2017,

Acceptance 23-06-2017, Published 24-07-2017.

Corresponding Author:

Dr. V. Sreenivasulu,

\#6-4-53-1, Maruthi Nagar,

Anantapuramu, Andhra Pradesh.

E-mail: drsreenivasuluvemula9@gmail.com

DOI: $10.14260 /$ jemds/2017/947 opportunistic infections have been significantly reduced. The risk of the specific adverse effects varies from drug to drug, regime to regime and patient to patient. Due to the ongoing development of newer antiretroviral drugs, it become much more important to understand and recognise the various adverse effects for better management.

Despite HAART therapy has been introduced in India since many years, there are only very few studies have been comprehensively looked into various adverse effects and majority of the studies have been limited to certain aspects of whole spectrum of adverse effects. In this study, various adverse effects related to HAART drugs among Indian patients have been studied prospectively.

\begin{tabular}{|c|c|c|}
\hline Name & Dosage & Adverse Effect \\
\hline \multicolumn{2}{|c|}{ Nucleoside Reverse Transcriptase Inhibitors } \\
\hline Zidovudine & $\begin{array}{c}300 \mathrm{mg} \text { b.i.d. tablet; 10 } \\
\mathrm{mg} / \mathrm{mL} \text { oral, IV solution }\end{array}$ & $\begin{array}{c}\text { Nausea, vomiting, } \\
\text { headache, asthenia, } \\
\text { anaemia, neutropaenia }\end{array}$ \\
\hline Stavudine & $\begin{array}{c}40 \mathrm{mg} \text { b.i.d. tablet; 1 } \\
\mathrm{mg} / \mathrm{mL} \text { oral solution }\end{array}$ & $\begin{array}{c}\text { Peripheral } \\
\text { neuropathy, } \\
\text { pancreatits, lactic }\end{array}$ \\
\hline
\end{tabular}




\begin{tabular}{|c|c|c|}
\hline & & $\begin{array}{c}\text { acidosis, lipoatrophy, } \\
\text { hyperlipidaemia }\end{array}$ \\
\hline Lamivudine & $\begin{array}{c}150 \mathrm{mg} \text { q.i.d. tablet; } 10 \\
\mathrm{mg} / \mathrm{mL} \text { oral solution }\end{array}$ & Minimal toxicity \\
\hline Tenofovir & 300 mg q.i.d. tablet & $\begin{array}{l}\text { Nausea, vomiting, } \\
\text { diarrhoea, headache, } \\
\text { asthenia, renal } \\
\text { insufficiency }\end{array}$ \\
\hline \multicolumn{3}{|c|}{ Non-Nucleoside Reverse Transcriptase Inhibitors } \\
\hline Nevirapine & $\begin{array}{c}200 \mathrm{mg} \text { tablet b.i.d.; } 10 \\
\mathrm{mg} / \mathrm{mL} \text { oral solution }\end{array}$ & Rash, hepatitis \\
\hline Efavirenz & $600 \mathrm{mg}$ q.i.d. tablet & $\begin{array}{c}\text { Rash, CNS (vivid } \\
\text { dreams, somnolence, } \\
\text { confusion, visual } \\
\text { hallucinations) }\end{array}$ \\
\hline \multicolumn{3}{|c|}{ Protease Inhibitors } \\
\hline Indinavir & 800 mg b.i.d. tablet & $\begin{array}{c}\text { Nephrolithiasis, } \\
\text { nausea, indirect } \\
\text { hyperbilirubinaemia, } \\
\text { hyperlipidaemia, } \\
\text { hyperglycaemia } \\
\end{array}$ \\
\hline Ritonavir & $\begin{array}{l}100 \mathrm{mg} \text { tablet soft } \\
\text { jelatin capsule }\end{array}$ & $\begin{array}{l}\text { Nausea, vomiting, } \\
\text { diarrhoea, asthenia, } \\
\text { oral parasthaesia, } \\
\text { hyperlipidaemia, } \\
\text { hyperglycaemia }\end{array}$ \\
\hline \multicolumn{3}{|c|}{ Integrase Inhibitors } \\
\hline Raltegravir & $400 \mathrm{mg}$ b.i.d. tablet & $\begin{array}{c}\text { Nausea, diarrhoea, } \\
\text { headache, myopathy/ } \\
\text { rhabdomyolisis }\end{array}$ \\
\hline \multicolumn{3}{|c|}{ Chemokine Receptor (CCR5) Antagonist } \\
\hline Maraviroc & $150 \mathrm{mg}$ b.i.d. tablet & $\begin{array}{c}\text { Constipation, } \\
\text { dizziness, infection, } \\
\text { rash }\end{array}$ \\
\hline \multicolumn{3}{|c|}{ Fusion Inhibitor } \\
\hline Enfuvirtide & 90 mg SC Inj. b.i.d. & $\begin{array}{l}\text { nj. site reactions (pain, } \\
\text { erythaema, induration, } \\
\text { nodule) }\end{array}$ \\
\hline
\end{tabular}

With the advent of HAART, HIV-1 infection is now manageable as a chronic disease in the patients who have access to medication and achieve durable virologic suppression.

6 classes of antiretroviral agents exist. Each class targets a different step in a viral lifecycle as the virus infects CD4 T lymphocytes and other target cells. The use of these agents in a practice largely dictated by their ease or complexity of use and side effect profile and clinical preference.

\section{Commonly used Drugs in HAART Therapy-}

Currently, the National Programme provides the following combination for first line regimes.

1. First choice- Zidovudine (AZT) + lamivudine (3TC) + nevirapine (NVP) (for the patients with $\mathrm{HB}>8 \mathrm{gm} \%$ ).

2. Second Choice- Tenofovir (TDF) + lamivudine (3TC) + efavirenz (EFV).

3. Third Choice- Stavudine $(\mathrm{d} 4 \mathrm{~T})+$ lamivudine $(3 \mathrm{TC})+$ nevirapine (NVP)/efavirenz (EFV).

\section{Objectives}

1. To study prospectively various HAART drugs-induced adverse reactions among HIV patients within 6 months of therapy.

2. To evaluate the correlation between adverse drug reactions with various demographic factors, clinical symptoms at the time of initiation of treatment, CD4 count at baseline various HAART regime.

\section{MATERIALS AND METHODS}

The study was conducted during the period from January 2015 to October 2016 at ART Center, Government General Hospital, Anantapur, Andhra Pradesh.

During the study period, 200 HIV patients who fulfilled the NACO Guidelines for HAART therapy were started on treatment and recruited for the study with following inclusion criteria. All HIV positive patients irrespective of associated opportunistic infections, those patients who started HAART therapy within 6 months of initiation of study were also recruited. None of the patients were excluded unless they are not willing to participate in the study.

\begin{tabular}{|c|c|c|c|}
\hline $\begin{array}{l}\text { Classification of } \\
\text { HIV Associated } \\
\text { Clinical Diseases }\end{array}$ & $\begin{array}{c}\text { WHO } \\
\text { Clinical } \\
\text { Stage } \\
\end{array}$ & $\begin{array}{c}\text { CD4 Test } \\
\text { not } \\
\text { Available } \\
\end{array}$ & $\begin{array}{l}\text { CD4 Test } \\
\text { Available }\end{array}$ \\
\hline Asymptomatic & 1 & Do not treat & $\begin{array}{l}\text { Start ART if CD4 } \\
<350 / \text { cu. mm. }\end{array}$ \\
\hline Mild symptoms & 2 & Do not treat & $\begin{array}{l}\text { Start ART if CD4 } \\
<350 / \text { cu. } \mathrm{mm} .\end{array}$ \\
\hline $\begin{array}{l}\text { Advanced } \\
\text { symptoms }\end{array}$ & 3 & Treat & $\begin{array}{l}\text { Start ART } \\
\text { irrespective of } \\
\text { CD4 count }\end{array}$ \\
\hline Severe symptoms & 4 & Treat & $\begin{array}{c}\text { Start ART } \\
\text { irrespective of } \\
\text { CD4 count }\end{array}$ \\
\hline \multicolumn{4}{|c|}{$\begin{array}{l}\text { Table 1. NACO/WHO } 2015 \text { Guidelines } \\
\text { for Initiation of the HAART }\end{array}$} \\
\hline
\end{tabular}

All the patients who were attending the ART Centre OPD were interviewed by single investigator and details were entered in the predesigned proforma for subsequent analysis of the data.

Details about various demographic information, clinical features with regards to HIV with or without associated OI. All the patients underwent detailed clinical examination as per proforma. All newly-recruited patients came for the followup at 1, 3 and 6 months. At every followup visit underwent detailed clinical evaluation with special emphasis on any new symptoms that has been observed after initiation of HAART therapy or any worsening of pre-existing symptoms. Specialist's opinion was taken regarding various clinical features such as peripheral neuropathy, nightmares, dermatological manifestations, etc. All the investigations were done as per NACO Guidelines done at our central laboratory. We grouped the HAART regime basically into 2 types based on the use of nevirapine based regime$\mathrm{AZT}+3 \mathrm{TC}+\mathrm{NVP}$, efavirenz-based regime- $\mathrm{TDF}+3 \mathrm{TC}+\mathrm{EFV}$.

Investigations include complete haemogram, which include $\mathrm{Hb} \%, \mathrm{RBC}$ indices, $\mathrm{TC}, \mathrm{DC}$, platelet count, peripheral smear morphology, blood sugar and lipid profile, if patient on protease inhibitors, urea and creatinine, if renal dysfunction is considered, liver function tests was done at baseline 1,3 and 6 months. Serum lactate, anion gap estimation and ABG was done those who presented with clinical signs and symptoms of lactic acidosis. CD4 counts, VDRL, HbsAg and HCV was done as per NACO Guidelines. The study was approved by hospital ethics committee. Descriptive statistical analysis was carried out in present study. Results on continuous measurement are presented on mean +/- SD. 
Results on categorical measurements are presented in number (\%). Chi-square test has been used to find out the significance of study parameters on categorical scale between 2 and more groups.

\section{RESULTS}

We evaluated the correlation between lower CD4 counts with various demographic factors by dividing the CD4 counts into $<100$ cells/cu. mm.- 101-200 cells- $>200$ cells. In our study, the younger age population (30-50 yrs.) was severely immunocompromised with CD 4 count $<200$ cells/cu. mm. Out of 73 individuals in the age category is $21-30$ years, more than half of them (38 out of 73 ) had CD 4 count $<200$ cells/cu. $\mathrm{mm}$. and 15 out of these $38 \mathrm{had}<100$ cells/cu. mm. In the age category of 31-40 years, 54 of 72 had CD4 count $<200 / \mathrm{cu}$. $\mathrm{mm}$. Among them, $32 \mathrm{had}<100 / \mathrm{cu}$. mm. Between $41-50$ yrs. of age, 26 of 38 had count CD $4<200 / \mathrm{cu}$. mm. Among them, 12 had $<100 / \mathrm{cu}$. mm. Interestingly, all individuals (5) between 61-70 yrs. had CD 4 count $<200 \mathrm{cu}$. $\mathrm{mm}$ and 3 of these 5 are severely immune compromised with CD4 count $<100 / \mathrm{cu}$. $\mathrm{mm}$. Thus, in our study, younger age individuals had more severe immunodeficiency by the virtue of lower CD4 counts $(\mathrm{p}=0.011)$.

We found that in our population, male gender had significantly lower CD4 count than female $(p=0.05)$. Out of 109 male patients studied, 78 had CD $4<200$ cells/cu. mm. Nearly, half of them had $<100$ cells/cu. mm. Among the female patients, $54 \%$ had $<200$ cells/cu. mm. Severe immunodeficiency with count $<100$ cells/cu. mm was observed in 23 of 52 patients.

The other demographic factors such as educational status $(\mathrm{p}=0.283)$, occupation $(\mathrm{p}=0.802)$, income status $(\mathrm{p}=0.059)$ didn't show any statically significant correlation with CD4 count. We analysed the correlation between presenting clinical symptoms with baseline CD4 count. Most of the common symptoms such as fever $(\mathrm{p}=0.017)$, weight loss (0.058), loss of appetite (0.017), cough (0.074), diarrhoea (0.583), etc., correlated significantly with lower CD4 counts. We didn't notice any statically significant association between lower BMI and low CD4 counts.

We had 111 patients with various forms of OI (PTB, Herpes zoster, etc.). 76 patients had CD4 $<200 / \mathrm{cu}$. mm. and 35 had CD $4>200 / \mathrm{cu}$. mm. Severe immunodeficiency with CD4 $<100$ was seen in 45 of 76 . There was significant correlation between lower CD4 counts and higher prevalence OI.

In our study, the overall prevalence of early ADR within 6 months of initiation of HAART was $60 \%$ (120 of 200). Overall, there are 255 ADR events in these 120 patients. The most common ADR was related to involvement of GI system. Nausea and vomiting was prevailed in 57 events (22.4\%). The symptoms of acute gastritis such as dyspepsia, retrosternal burning sensation, epigastric discomfort, pain in abdomen was seen in $44(17.3 \%)$. Only 3 had acute drug-induced hepatitis.

Overall, 40.8\% ADR was related to GI system. Out of 255 events, 66 were related to fatigue (25.9\%). Most of these events occur during initial period of HAART. Anaemia was observed in 44 events (17.3\%). Majority of them are on AZT. Dermatological manifestations such as various types of skin rashes and hyperpigmentation of nails was observed in 18 events (11.1\%). Most of them were NVP-based regime. 13 events are characterised by dull aching holocranial headache (5.1\%). We had an immune reconstitution inflammatory syndrome in 4 patients (1.6\%). All 4 patients with immune reconstitution inflammatory syndrome has coexisting TB. Peripheral neuropathy was observed in 2 patients $(0.8 \%)$. Both of them were on STV-based regimen. One of the patients on EFV complain of nightmares, disturbed sleep and excessive daytime sleepiness. We had 2 patients of signs and symptoms of lactic acidosis presented with complaints of nausea, vomiting and abdominal discomfort. All patients had increased anion gap, elevated fasting serum lactate levels. One of these on STV, another on AZT. However, the patients who had loss of weight as an initial presenting symptom had a trend towards statistically significant correlation with high prevalence of ADR ( $\mathrm{p}=0.088)$. Leucopenia was prevalent in $56.5 \%$ of our patients. Majority of our patients showed the lower HDL levels.

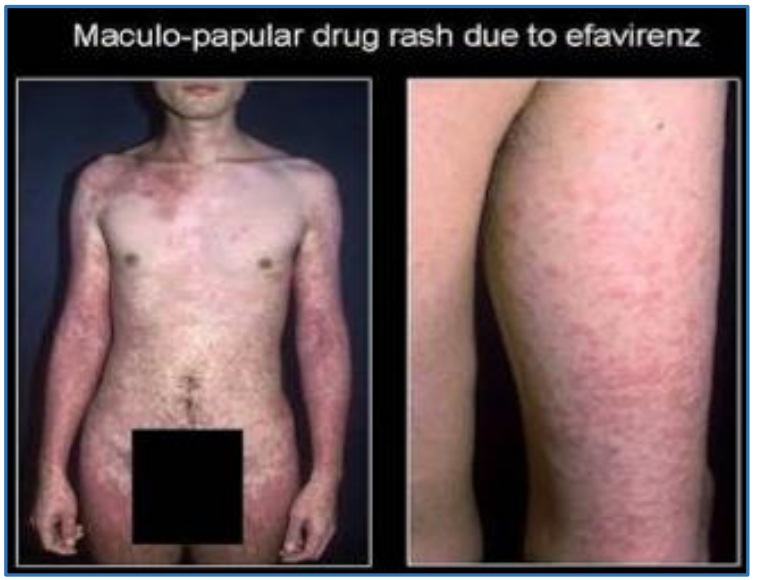

Maculopapular Drug Rash Due to Efavirenz

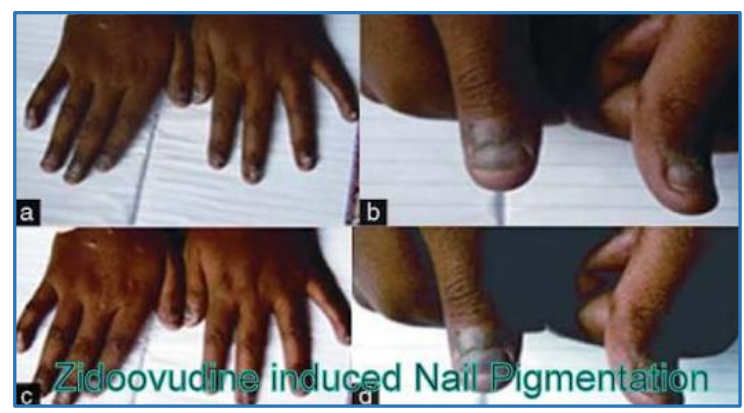

Zidovudine-Induced Nail Pigmentation

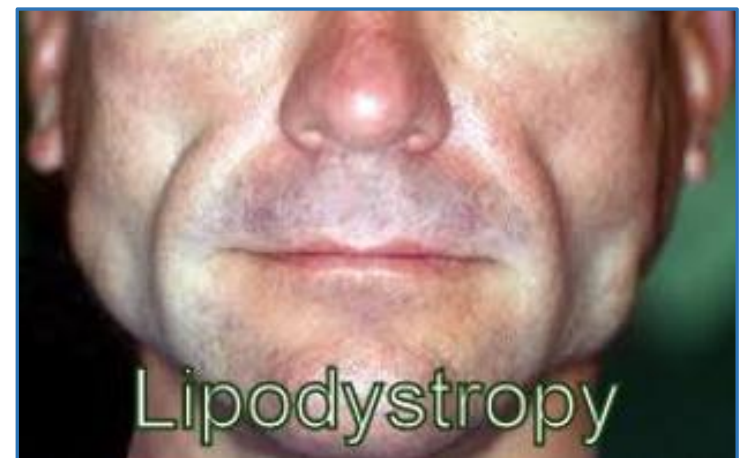

Lipodystrophy 


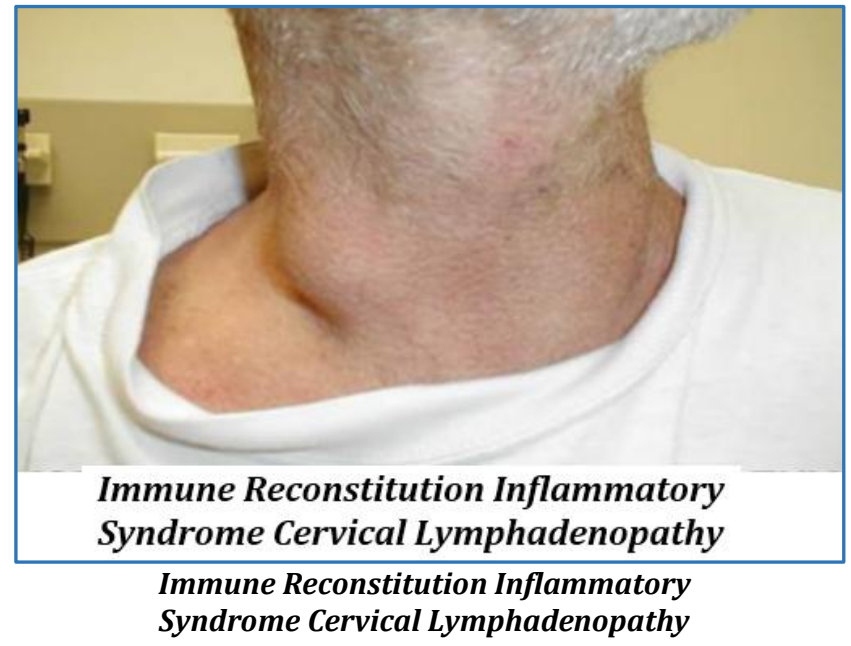

\section{DISCUSSION}

We found most common ADR was related to involvement of GI system manifestations such as acute gastritis, nausea, vomiting as well as drug-induced hepatitis ${ }^{1}$ (40.8\%). In contrast to our observation, Harminder Singh et al (2009) reported peripheral neuropathy as most common ADR (31.64\%). Kumara Swamy et al (2002) and Ajay Sharma et al ${ }^{2}$ (2008) reported cutaneous manifestations as most common ADR $(15.2 \%$ and $44.4 \%$, respectively). This difference in various studies could be due to difference in the drugs used during the initiation of HAART and different periods of follow up.

Most of the HAART drugs from NRTI and PI are associated with GI and hepatic toxicities, but cutaneous ADR are most common with NNRTI's.

None of the studies have looked at the prevalence of the fatigue after the initiation of HAART therapy, which could be one of the commonest yet unrecognised ADR, which may force the patient to default therapy. In our study, second most common ADR was fatigue as evaluated by questionnaire (25.9\%). The overall prevalence of anaemia in the present study was $17.3 \%$ and $15 \%$ of them are severe anaemia. Harminder Singh, ${ }^{3}$ Kumaraswamy and Ajay Sharma reported anaemia as ADR in their $13.3 \%, 5.4 \%$ and $20 \%$ of their patients respectively. All of our patients were treated with iron and folic acid supplementation. This observation was not made in earlier studies.

\begin{tabular}{|c|c|c|}
\hline $\begin{array}{l}\text { Pattern of Adverse } \\
\text { Reactions }\end{array}$ & $\begin{array}{c}\text { Number of Events } \\
(n=255)\end{array}$ & Percentage \\
\hline Fatigue & 66 & 29.5 \\
\hline Nausea/vomiting & 57 & 22.4 \\
\hline Gastritis & 44 & 17.3 \\
\hline Anaemia & 44 & 17.3 \\
\hline Rashes & 18 & 7.1 \\
\hline Headache & 13 & 5.1 \\
\hline $\begin{array}{l}\text { Immune reconstitution } \\
\text { inflammatory syndrome }\end{array}$ & 4 & 1.6 \\
\hline Hepatitis & 3 & 1.2 \\
\hline Lactic acidosis & 2 & 0.8 \\
\hline Peripheral neuropathy & 2 & 0.8 \\
\hline Nightmare & 1 & 0.4 \\
\hline ADR with drugs for OI & 1 & 0.4 \\
\hline
\end{tabular}

The prevalence of peripheral neuropathy in our cohort $(0.8 \%)$ was lower compared to other studies. Harminder
Singh reported it as most common ADR in their cohort who were followed up for 2 years. Similarly, Ajay Sharma reported $22.2 \%$ and Kumaraswamy 9\%. All these authors including present study found that stavudine-based regimes commonly associated with higher prevalence of peripheral neuropathy. The reasons for lower prevalence in our study could be due to shorter follow up and less number of patients on stavudine regime.

Lactic acidosis is one of the severe forms of ADR seen with AZT and stavudine. In our current study, there were 2 patients who have elevated lactate levels with increased anion gap. Ajay Sharma reported it in 1 in 90 patients. The prevalence of lactic acidosis varies from $10-20 \%$ (Tesiorowsky AM). These patients treated with change in the regime after discontinuation of HAART for short period.

In our study, immune reconstitution inflammatory syndrome was observed in 4 patients (1.6\%) and all of them were presented with tuberculosis. Immune reconstitution inflammatory syndrome was reported in $22.2 \%$ of patients by Ajay Sharma. 11 patients presented with Herpes zoster, 5 with Herpes simplex and 4 patients with new onset of TB in his study.

Lipodystrophy commonly associated with treatment of PI and stavudine. Harminder Singh and Ajay Sharma reported it in $20 \%$ and $14.5 \%$ of their patients, respectively. In contrast, we did not notice lipodystrophy in any of our patients. This could be possibly due to non-utilisation of PI and less number of patients on STV.

Nightmares and vivid dreams were observed in one of our patients on EFV-based regime. Similarly, Ajay Sharma observed the same in 2 of their patients on EFV.

In this study, we attempted to correlate between various ADR and baseline CD4 count instead of medium CD4 count at the time of event. Except anaemia, which showed a positive trend towards statistically significant correlation with lower CD4 count at the time of initiation, none of the other individual events correlated significantly with CD4 counts. Harminder Singh concluded that lower CD4 count correlated significantly with overall prevalence of ADR with HAART.

We also attempted the correlation between various demographic factors with the prevalence of ADR. None of the demographic factors influenced the prevalence of ADR in our study.

Similarly, when we analysed the correlation between the BMI and stage of the disease at the time of inclusion, there was no statically significant relation. However, those patients who had loss of weight at the time of initiation of therapy showed a positive trend towards higher chances of ADR.

There were few attempts to correlate between regimen selected for initiation of HAART and prevalence of ADR. The skin rashes were significantly correlated with NVP-based regime and peripheral neuropathy had significant correlation with stavudine-based regimen.

In this study, lower CD4 counts significantly correlated with younger population and male gender suggesting that these subjects were probably more sexually active acquiring more virulent form of virus, which leads to more severe immunosuppression. The clinical symptoms at presentation correlated significantly with lower CD4 counts suggesting lower immune status. Similarly, the more severe the disease stage at presentation, the lower CD4 counts. Opportunistic infections occurred more commonly with lower CD4 counts. 
All these findings only reinforced the already established phenomenon with respect to lower CD4 counts and their consequences.

\section{CONCLUSION}

ADR common even with short duration of HAART therapy. Gastrointestinal manifestations are more common during early part of therapy. Fatigability due to HAART is also one of the common ADR, which needs to be systemically addressed to increase the compliance with the treatment. Some of the authors observed female gender are more susceptible to ADR. We did not notice this gender difference. ADR are not influenced by age, educational status, income, lower BMI, advanced stage of disease and lower CD4 count at the time of initiation of therapy. None of our patients were noncompliance with HAART despite of $2 / 3$ of them suffered from ADR. This suggests that early reactions can be effectively managed by early recognition and treatment, which will increase success rate of HAART and quality of life. To optimise adherence and efficacy, clinicians must focus on preventing this ADR whenever possible and distinguishing those that are self-limited from those that are potentially serious such as lactic acidosis. More research is needed to develop low-cost investigations and algorithm for prediction of ADR to existing regimes along with generations of more efficient and less toxic drugs.

\section{REFERENCES}

[1] den Brinker M, Wit FW, Wetheim-van Dillen PM, et al. Hepatitis $\mathrm{B}$ and $\mathrm{C}$ virus co-infection and the risk for hepatotoxicity of highly active antiretroviral therapy in HIV-1 infection. AIDS 2000;14(18):2895-902.

[2] Sharma A, Vora R, Modi M, et al. Adverse effects of anti-retroviral treatment. Indian Journal of Dermatology, Venerology, Leprology 2008;74(3): 234-7.

[3] Singh H, Dulhani N, Tiwari P, et al. A prospective, observational cohort study to elicit adverse effects of antiretroviral agents in a remote resource-restricted tribal population of Chhattisgarh. Indian Journal of Pharmacology 2009;41(5):224-6. 